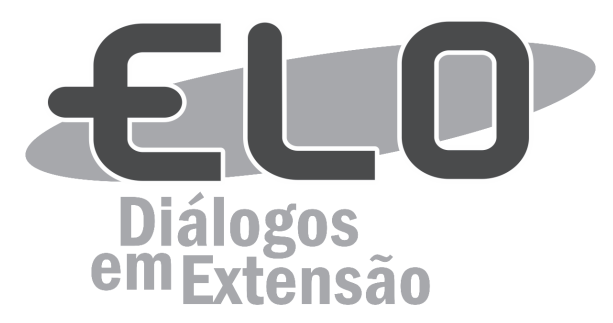

\title{
Apontamentos sobre o processo participativo em cooperativas de Programas de Reativação Econômica: o caso da Coopescabraúna ${ }^{1}$
}

\author{
Bruno Costa da Fonseca²; Cristina Caetano de Aguiar; Edson Arlindo Silva4;
} Riverson Moreira dos Santos ${ }^{5}$; Daniele Pereira Linhares ${ }^{6}$

\begin{abstract}
Resumo: Este trabalho teve por escopo analisar o processo de participação na Cooperativa de Pescadores Atingidos pela Barra do Braúna (COOPESCABRAÚNA), localizada no município de Laranjal (MG), Brasil. Ligada ao Programa de Reativação Econômica, esse tipo de cooperativa destina-se a viabilizar projetos de geração de renda às famílias atingidas por barragens. Para a realização do estudo, foram utilizadas entrevistas semiestruturadas, observação participante e pesquisa documental. Dentre os principais resultados, verificouse uma divergência para com os princípios da participação social e econômica que deveriam ser encontrados, mormente, em cooperativas tradicionais, fruto das especificidades da COOPESCABRAÚNA, dentre as quais o fato de que a produção dos peixes é feita de forma profissional em tanques-rede não havendo participação dos cooperados no processo e, via de regra, a comercialização de forma individual é mais viável não possibilitando o ganho em escala, uma das principais vantagens dos empreendimentos cooperativos.
\end{abstract}

Palavras-chave: Participação. Cooperativismo. COOPESCABRAÚNA.

Área Temática: Cooperativismo.

\section{Notes on the participatory process in Cooperatives of Economic Reactivation Programs: the case of Coopescabraúna}

Abstract: This work had the purpose of analyzing the process of participation in the Cooperative of Fishermen affected by Barra do Braúna (COOPESCABRAUNA), located in the municipality of Laranjal (MG), Brazil. Linked to the Economic Reactivation Program, this type of cooperative is intended to make feasible income generation projects for families affected by dams. For the study, semi-structured interviews, participant observation and documental research were used. As main results, there was a divergence with the principles of social and economic participation, mainly found in traditional cooperatives, as a result of the specificities of COOPESCABRAUUNA, among which: the production of fish is done professionally in tanks-nets participation of the cooperative in the process; and, as a rule, commercialization on an individual basis is more viable, not allowing gain in scale, one of the main advantages of cooperative ventures.

Keywords: Participation. Cooperativism. COOPESCABRAÚNA.

\footnotetext{
${ }^{1}$ Este artigo é parte dos resultados alcançados na pesquisa "Análise do processo de participação no Programa de Reativação Econômica: o caso da COOPESCABRAUNA - Cooperativa de Pescadores da Barra do Braúna", uma parceria entre o Departamento de Administração, Letras e Artes da Universidade Federal de Viçosa e Observatório Mineiro de Cooperativismo. Os principais resultados e os documentos que deram origem a este artigo podem ser encontrados em < http:// www.sede.mg.gov.br/pt/ >

${ }^{2}$ Doutorando em Ciências Sociais em Desenvolvimento, Agricultura e Sociedade pela Universidade Federal Rural do Rio de Janeiro; Rua Padre André Moreira, 305 , ap. 403, Méier, Rio de Janeiro (RJ). Telefone: (21)996010061. E-mail: brunodogma@gmail.com.

${ }^{3}$ Professora da Faculdade Dinâmica do Vale do Piranga. Mestre em Administração Pública pelo Departamento de Administração e Contabilidade da Universidade Federal de Viçosa.

${ }^{4}$ Professor doutor da Faculdade de Ciências Integradas do Pontal da Universidade Federal de Uberlândia. Atua também como Professor-Pesquisador e Orientador junto ao Programa de Pós-Graduação em Gestão Organizacional da Universidade Federal de Goiás - Campus Catalão.

${ }^{5}$ Bacharel em Cooperativismo pelo Departamento de Economia Rural da Universidade Federal de Viçosa.

${ }^{6}$ Estudante de administração pelo Departamento de Administração e Contabilidade da Universidade Federal de Viçosa.
} 


\section{Notas sobre el proceso de participación en las sociedades cooperativas programa de reactivación económica: el caso de Coopescabraúna}

Resumen: Este trabajo buscó analizar el proceso de participación en la Sociedad Cooperativa de los Pescadores Afectados por la Barra do Braúna (COOPESCABRAÚNA), situada en el municipio de Laranjal $(M G)$, Brasil. Conectado con el Programa de Reactivación Económica, este tipo de sociedad cooperativa está destinada a los proyectos de generación de ingresos para las familias afectadas por las presas. Para la realización del estudio se utilizó entrevistas semiestructuradas, observación participante y la investigación documental. Entre los principales resultados se verificó una divergencia con los principios de la participación social y económica que se encuentran, mayormente, en las cooperativas tradicionales, resultante de las especificidades de la COOPESCABRAÚNA, entre los cuales: la producción de pescado se hace de una manera profesional en estanques-rede sin la participación de los cooperativistas en el proceso; $y$, usualmente, la comercialización individual es más viable no posiblitando la ganacia en demasia, una de las principales ventajas de las sociedades cooperativas.

Palabras clave: Participación. Cooperativismo. COOPESCABRAÚNA.

\section{Introdução}

O cooperativismo, materializado pelos empreendimentos associativos, tem sido uma alternativa para a sustentabilidade socioeconômica de grupos mais ou menos coesos em diversos lugares do mundo. Como forma de enfrentar crises, alternativas ao desemprego ou pela simples união da força de trabalho, as cooperativas se diferenciam das 'empresas de capital' quando colocam os sujeitos no centro do negócio, ou seja, a participação social e econômica se torna a força motriz do empreendimento (SCHNEIDER, 1999; VALADARES, 2004; KLAES, 2007).

Contudo, a proficuidade do processo de participação, para além do tipo ideal de cooperativismo, tem se tornado um desafio, seja pelo alto grau de profissionalização da gestão, exigida em alguns empreendimentos, seja pela falta de interesse dos cooperados ou até mesmo pela emergência das "cooperativas fantasmas" conhecidas também como "coopergatos"7. Enfim, podem ser infindáveis os motivos pelo malogro do processo participativo.

Todavia, este artigo pretende trazer a luz das discussões uma análise do processo de participação em uma cooperativa vinculada a um Programa de Reativação Econômica (PRE) que imprime desafios de gestão relativamente diferentes de outros casos mais comuns no Brasil.

Nesse sentido, os $\mathrm{PRE}^{8}{ }^{8}$ são projetos de geração de renda, destinados a famílias atingidas pela construção de barragens, que têm, com efeito, a perda parcial ou total dos meios de produção de outrora. Isto se dá, pois, a maior parte das famílias atingidas constituem comunidades rurais, ribeirinhas ou de agricultores familiares que dependem quase que exclusivamente do rio e da terra - inundada pela implantação do empreendido hidrelétrico - para sobreviver.

Nesse caso, o cooperativismo surge como uma forma de reintegrar essas famílias em projetos de geração de renda e é fruto de uma tentativa de resolução de conflito instaurado entre as famílias impactadas e o empreendedor responsável pela construção do projeto de barramento. Deste processo surgem alguns problemas conflituosos relacionados, de forma mais direta, às instâncias de participação do empreendimento. Esses conflitos, neste estudo, foram percebidos nos aspectos inerentes à produção e comercialização, incutindo efeitos significativos também sobre a participação social dos cooperados.

Especificamente, analisou-se o caso da Cooperativa de Pescadores Atingidos pela Barra do Braúna (COOPESCABRAÚNA), localizada no município de Laranjal, Minas Gerais, Brasil. Esta cooperativa foi criada a partir do PRE Aliança, atinente ao processo de negociação entre a empresa Brookfield Energia Renovável e a Comissão dos atingidos Por Barragens de Barra do Braúna, nome da Usina Hidrelétrica de Energia que atingiu direta e indiretamente os municípios de Cataguases, Leopoldina e Recreio no Estado de Minas Gerais.

O PRE pretende, por intermédio da fomentação de empreendimentos autogestionários, gerar renda para os agricultores familiares, meeiros, areeiros e ex-pescadores artesanais. Destarte, a COOPESCABRAÚNA intenta, de forma mais específica, atender dois grupos de ex-pescadores distintos que viviam da pesca artesanal, os profissionais e os amadores, ambos reconhecidos pelo Ministério da Pesca e Aquicultura. O projeto prevê o envolvimento de aproximadamente 40 famílias atingidas. 
Cabe ressaltar, entretanto, que a mudança de pescadores artesanais (individual) para cooperados em um empreendimento coletivo de produção de peixe em tanques-rede é o principal elemento problematizador deste artigo. Isto é, percebeu-se uma situação-problema passível de averiguação empírica, com destaque para o processo de mudança da atividade artesanal para uma atividade altamente tecnificada, com padrões de produção tecnológicos complexos. Ao passo que a verificação empírica via, pesquisa exploratória, se estende a gestão da cooperativa e dá pistas sobre os principais problemas de participação deste novo tipo de cooperativismo.

Em verdade, o empreendimento em si não é novo, mas o processo de construção de um empreendimento que vem para amenizar um processo conflituoso e que talvez não aconteceria de forma natural, ou seja, por iniciativa dos pescadores. Portanto, se tornou importante responder a seguinte indagação de pesquisa: Quais são os principais entraves da participação, sobretudo tendo em vista a produção e comercialização da COOOPESCABRAÚNA, que evidenciam um processo de cooperação diferenciado para as cooperativas oriundas do Programa de Reativação Econômica?

Para tanto, este texto contará com as seguintes partes além dessa introdução: a) uma breve explanação sobre processos de cooperação e participação em cooperativas; b) os métodos utilizados nessa pesquisa; c) às análises dos dados pela perspectiva da participação na comercialização e na produção; d) algumas conclusões finais e por fim as e) referências bibliográficas utilizadas neste estudo.

\section{Cooperação e participação}

Pensar em elementos da cooperação é pensar o próprio surgimento da humanidade. Inicialmente a biologia trata de indícios da cooperação entre os seres vivos mais antigos de nossa sociedade, seja em formas micro-orgânicas, seja em formas mais evoluídas de vida. Posteriormente, disciplinas como a sociologia e a antropologia apontam para formas de cooperação que são frutos de processos sociais mais dinâmicos e que evidenciam uma racionalidade típica do homossapiens, ser pensante, que encontra na solidariedade formas de alcançar anseios individuais. Em contraposição às ideias de cooperação entre os seres vivos Darwin defendia a teoria de que as criaturas são dotadas, por natureza, de uma competição egoísta, fruto de uma busca intensiva por recursos alimentares e sexuais (LENCASTRE, 2010).

Não obstante as preposições sobre as origens e naturalidade da cooperação, destacam-se períodos históricos em que a solidariedade entre os seres humanos se aproximou cada vez mais de sociedades e empreendimentos associativos, que invoca, com feito, as origens das cooperativas modernas como se tem hoje. O marco do Socialismo Utópico pode ser um bom ponto de partida. Em meados do século XIX a sociedade vivia uma intensa pressão que o capitalismo exercia sobre a relação trabalho e meios de produção. O processo de industrialização provocou em muitos lugares do mundo, mas, sobretudo na Europa, o inchamento das cidades, bem como os péssimos salários e condições desumanas de trabalho das classes proletárias. Destarte, passou a se pensar "novas" formas da relação de trabalho e produção que superassem as crises socioeconômicas pelas quais a sociedade passava na época.

As experiências que mais contribuíram para a institucionalização do cooperativismo tinham como percussores os seguintes Socialistas Utópicos:

1. Robert Owen (1771 - 1858): Britânico - que posteriormente passou a morar nos Estados Unidos criou a primeira colônia socialista de New Harmony que funcionava como uma "comunidade cooperativa", igualitária, sustentada por estímulos de cooperação econômica, política e ideológica. Em termos de "sociedade" estava implantada a primeira experiência de comunidades solidárias. Todavia, este novo ideal não perpetuou, mas sua contribuição para as questões sociais foram de tamanha importância, e suas ideias utópicas inspiraram movimentos de trabalho e produção coletiva em todo o mundo (PINTO, 2009).

2. Charles Fourier (1772 - 1837): Nascido na França, foi responsável pela criação dos Falanstérios, grupos organizados em vida comum. Segundo Fourier, as Falanges reuniriam todos os caracteres inerentes aos seres humanos ${ }^{9}$ e desta forma os processos de coletividade e harmonia econômica/ social obteriam êxito (KLAES, 2007).

3. Louis Blanc (1811 - 1882): Também nascido na França, Blanc combatia o liberalismo econômico. Para ele, os processos coletivos (associações principalmente, que iriam substituir as empresas privadas no futuro) deveriam estar subjugados ao Estado, pois de outra forma estariam destinadas ao malogro (PINTO, 2009). 
4. Joseph Proudhon (1809 - 1865): Nascido também na França, Proudhon defendia a ideia de que o indivíduo sendo livre ${ }^{10}$ a sociedade voltaria aos processos naturais, refletindo em convivência harmônica e coletiva, anterior ao capitalismo contemporâneo. Sendo assim, neste tipo de sociedade não existiria a propriedade privada, nem a divisão de classes sociais, seria comandada apenas pelos princípios da união mútua (RÊGO, 2009).

5. Sismonde de Sismondi (1773 - 1842): Italiano, Sismondi apoiava a intervenção do Estado para manter o equilíbrio nos processos econômicos e sociais. Na prática sua luta se pautava na diminuição da exploração do trabalho e sua contribuição reflete diretamente na formação social do cooperativismo, sem haver total renúncia ao direito de propriedade privada (SANTOS, 2003).

6. Charles Gide (1847-1932): O francês Gide - criador da "Escola de Nimes", responsável pela disseminação das premissas do cooperativismo - tinha como principal ideal a luta pela justiça social, eliminação das desigualdades sociais e das mais diversas formas de exploração. Buscava a eliminação do lucro e do processo de apropriação dos excedentes, por meio da eliminação dos atravessadores, dos assalariados, do comércio e dos patrões (PINTO, 2009).

Os socialistas utópicos e suas experiências de processos coletivos foram, para uma boa parte dos pesquisadores (BIALOSKORSKI NETO, 2006; SALES, 2010; REISDORFER, 2014), as bases para o que viria a ser criado posteriormente como a primeira cooperativa moderna. Em 1844, na Inglaterra, ocorreu a criação da Rochdale Society of Equitable Pioneers (Sociedade dos Probos Pioneiros de Rochdale), onde vinte e oito tecelões se juntaram com o propósito de gerar renda diante das crises econômicas vividas na época. Este novo tipo de empreendimento buscava valores diferentes das empresas de capital, as decisões eram centradas em normas igualitárias e democratas, tendo as pessoas como principal finalidade, e não o lucro.

De acordo com Valadares (2004), ainda durante o século XIX, a experiência de Rochdale foi replicada em todo o mundo, com a criação de empresas comunitárias dedicadas as mais diversas atividades econômicas.

Na França e Inglaterra, surgiram às empresas cooperativas de trabalho, na Alemanha e na Itália, apareceram às primeiras cooperativas de crédito rural e crédito urbano, na Bélgica e países vizinhos, surgiram às primeiras organizações cooperativas de produção agropecuária. A partir dessa época, o cooperativismo, como proposta de organização empresarial na forma de empresas cooperativas, disseminou-se pelo mundo (VALADARES, 2004, p.16).

Com o surgimento das cooperativas, enquanto empreendimentos autogestionários e democráticos, alguns pressupostos da participação precisam ser evidenciados, inclusive enquanto categoria de análise nestes empreendimentos. Cabe destacar, nesse sentido, que uma sociedade cooperativa é tida como pluridimensional, o que as torna um tipo de organização complexa, consequentemente, diferente de outras formas de organizações convencionais, tendo em vista que tem por desafio cumprir objetivos tanto na ordem do social como na ordem do econômico.

Em outras palavras, dentre as principais características que as diferenciam das empresas mercantis consiste em sua dupla natureza, caracterizada por processos de cooperação interna e de competitividade externa, incutindo em instâncias destinadas a gestão social e econômica do empreendimento. Para Dahl (1990), por "Cooperativas Autogestionárias" entende-se empresas democraticamente geridas por todas as pessoas que nelas trabalham e aquelas que têm uma organização que visa atender aos critérios do processo democrático, ou seja, assegurar a igualdade política e a proteção dos direitos políticos dentro da empresa.

Na prática, a base da democracia é feita essencialmente pela participação, isto é, incide no envolvimento dos sujeitos na vida coletiva, portanto a participação é fundamental para os empreendimentos autogestionários. No entanto, Fontes Filho (2008), chama atenção para o fato de que a participação tem que acontecer em todas as fases da gestão do empreendimento, imprimindo, assim, uma participação que seja, por ele considerada de qualidade.

Embora a participação seja o elemento central de proficuidade dos empreendimentos associativos o que se tem revelado são desafios em diversas cooperativas do mundo, sobretudo nas cooperativas brasileiras.

Nesse contexto, diversos estudos (HOLZMANN, 2000; BIALOSKORSKI NETO, 2007; FONTES FILHO, MARUCI, OLIVEIRA, 2008) têm mostrado que o nível de participação dos cooperados em 
cooperativas é baixo e muitas vezes medido apenas pela participação dos cooperados em assembleias. Para Fontes Filho (2008), avaliar o nível de participação apenas pela presença nas assembleias é diminuir exponencialmente as possibilidades e a importância do envolvimento associativo nas cooperativas.

[...] A natureza da participação cooperativa não se mede somente através de critérios quantitativos, como através de taxas de presença às assembleias gerais, eleição dos dirigentes, etc. [...] A participação às assembleias não é mais do que uma participação formal, que, se não é complementada com outras modalidades de participação, compromete apenas transitória e superficialmente o associado com sua cooperativa (SCHNEIDER, 1999, p.196).

Dessa forma, a presença nas assembleias não pode ser considerada um bom indicador de participação. É preciso verificar outras instâncias e dinâmicas, não quantitativas, dentro da cooperativa, tal como as possibilidades de assumir cargos na cooperativa; a participação em atividades e eventos diversos, sobretudo àqueles que possibilitam assumir posições divergentes em uma discussão, manifestá-las e defendê-las publicamente; entre outras maneiras. Todavia, há de se considerar que a manifestação pública, por meio do uso da palavra, não é uma prática habitual, pois ela significa abrir mão do anonimato, expor sua individualidade perante o grupo, arriscar-se à crítica daqueles para quem fala, o que dificulta ainda mais o processo de participação nas cooperativas (HOLZMANN, 2000).

Tendo em vista que a pouca participação pode ser um dos elementos de insucesso das cooperativas, especialmente no que tangem às dinâmicas sociais, é preciso criar estímulos e canais para a mesma. Menegário (2000) aponta algumas saídas que estão pautados na disseminação das informações, na organização social e na conscientização dos cooperados, procedimentos que se tornam pré-requisitos fundamentais a uma participação mais efetiva do quadro social na gestão da cooperativa.

Por fim, ressalta-se, que, embora o tema da participação em cooperativas seja de suma importância, ainda existem poucos estudos empíricos e apontamentos teóricos sobre a questão. Birchall e Simmons (2004) propõem um modelo de análise a partir de três aspectos importantes: a) o primeiro considera os incentivos que estimulam a participação, caracterizado pelos recursos e capacidades do potencial de participação. Como exemplos têm o tempo, o dinheiro, as habilidades, o conhecimento e a confiança; b) o segundo aspecto é inerente à mobilização social, ou seja, a existência de questões que catalisam o interesse de atuar, como exemplo, a promoção de oportunidades de participar, e os esforços de recrutamento; e por fim c) o aspecto evidenciado pelo modelo denominado Mutual Incentives Theory (MIT).

De acordo com a teoria em discussão, duas abordagens explicam a propensão à motivação a participar, de forma individual e coletiva. Na individual encontram-se alguns aspectos que devem ser considerados, como os benefícios de se participar, os hábitos dessa prática, custos diretos e de oportunidade, todos esses fatores constituem os estímulos à participação. Na perspectiva coletiva, os fatores a serem considerados são a existência de objetivos comuns, a sensação de pertencimento e valores compartilhados e o senso de comunidade dado pela identificação com outros que vivem na mesma região ou têm situações semelhantes de outras naturezas, constituem os elementos que motivam à participação.

\section{Metodologia}

Este estudo se orientou por metodologias qualitativas no que se refere a coleta e análise dos dados. Outrossim, é classificado como um estudo de caso pois possibilitou fazer observações diretas e entrevista em um objeto de estudo que se analisou profundamente. Com a possibilidade de um exame detalhado de um ambiente, de um simples sujeito ou de uma situação em particular, permitiu seu amplo conhecimento, o que evidencia, com efeito, uma projeção de inferências para outros casos mais gerais (VERGARA 2005; GODOY, 2006; GIL, 2007),

Especificamente, sobre os métodos de coletas de dados, foram utilizadas entrevistas semiestruturadas, a observação participante e a pesquisa documental. De acordo com Lakatos e Marconi (1991) e Vergara (2005), a entrevista semiestruturada trata-se de uma técnica em que o entrevistador segue um roteiro previamente elaborado, mas pode sofrer alterações, o que exige do pesquisador domínio do referencial teórico. Para o caso estudado realizou-se entrevistas à $90 \%$ dos cooperados. 
A observação participante, por sua vez, consiste em uma técnica de coleta de dados que implica o convívio, o compartilhamento de uma base comum de comunicação e uma troca de experiências por intermédio dos sentidos humanos (olhar, falar, sentir, vivenciar) entre o pesquisador, os sujeitos observados e o contexto dinâmico de relações no qual os sujeitos vivem e que são por todos construídos e re-construídos a todo o momento (PERUZZO, 2009). Essa técnica foi possível por meio do acompanhamento do trabalho de assessoria realizado pelo Núcleo de Assessoria às Comunidades Atingidas por Barragens (Nacab) durante nove meses. Durante esse processo, os pesquisadores participaram de reuniões mensais na cooperativa, dos cursos de capacitação dos cooperados, em dias de despescas, em reuniões da diretoria da cooperativa e em reuniões interna do Nacab.

Além disso, foi de extrema importância o aprofundamento na pesquisa documental junto a cooperativa e ao Nacab, o que cunhou inferências importantes sobre o processo de negociação para elaboração do PRE e, por consequência, sobre a natureza da cooperativa que se tem hoje. Nesse sentido, a pesquisa documental é constituída pelo exame de materiais de natureza diversa, que ainda não receberam um tratamento analítico, ou que podem ser reexaminados, buscando-se novas interpretações complementares (GODOY, 2006). Cabe ao pesquisador explorar tais documentos de maneira a melhorar a compreensão do problema investigado.

E por fim, quanto a interpretação dos dados utilizou-se, sobretudo, a análise de conteúdo. Observase, baseados nos estudos de Bardin (1997, p.31), que a análise de conteúdo é definida como "[...] um conjunto de técnicas de análise das comunicações". Mais do que um instrumento, é um conjunto de técnicas e procedimentos marcado por uma grande disparidade de formas e adaptável a um amplo campo de aplicação. Esta técnica é uma dentre as diferentes formas de interpretar o conteúdo de um texto, documento ou entrevistas.

Em termos práticos foi realizado as seguintes etapas para análise do material recolhido: 1) Préanálise: seleção do material e a definição dos procedimentos a serem seguidos; 2) Exploração do material: implementação dos procedimentos definidos; 3) Tratamento dos dados e interpretação: geração de inferências e dos resultados da investigação, onde as suposições poderão ser confirmadas ou não.

\section{Resultados e discussões}

Os principais problemas de participação diagnosticados na pesquisa, se remetem a quatro questões específicas: participação no momento de criação da cooperativa; participação social; participação na produção e na comercialização da cooperativa. Todavia, este artigo pretende abordar, de forma mais precisa, os problemas relacionados a participação na produção e na comercialização da cooperativa, tendo em vista seus efeitos sobre a participação social o que por vezes é indissociável em termos de práticas e de análises empíricas.

\subsection{Participação na Produção}

A produção dos peixes na COOPESCABRAÚNA é feita de forma profissional em tanques-rede (Figura 1), logo, os pescadores artesanais, assim chamados antes da construção da hidrelétrica Barra do Braúna, passaram a ser piscicultores, o que gerou uma mudança de hábitos e uma perda de identidade dessa atividade profissional. Segundo Diegues (1995), a atividade da pesca está associada à forma de como esses pescadores adquirem o conhecimento e o desenvolvimento das habilidades necessárias para exercer essa atividade. Ainda para esse autor, a tradição é fator fundamental na pesca artesanal.

A questão da tradição está relacionada também ao cerne da própria pesca artesanal: o domínio do saber-fazer e do conhecer que forma o cerne da "profissão". Esta é entendia como o domínio de um conjunto de conhecimentos e técnicas que permitem ao pescador se reproduzir enquanto tal. Esse controle da "arte da pesca" se aprende com "os mais velhos" e com a experiência (DIEGUES, 1995, p.35).

Desse modo, a apropriação dos recursos hídricos, para fins de geração de energia elétrica, tem forçado pescadores artesanais a mudar o seu modo de vida. Os conflitos provocados pelas diferentes formas de apropriação dos recursos hídricos e as disputas do território das águas e dos peixes, estão provocando a extinção de uma categoria ocupacional e de um modo de vida particular, relacionado à pesca artesanal. Para Carvalho (2010) esta realidade se torna ainda mais preocupante ao levarmos em conta a solução encontrada pelo poder público para compensar esta situação vivida pelos pescadores, qual seja, o incentivo à prática da piscicultura. 


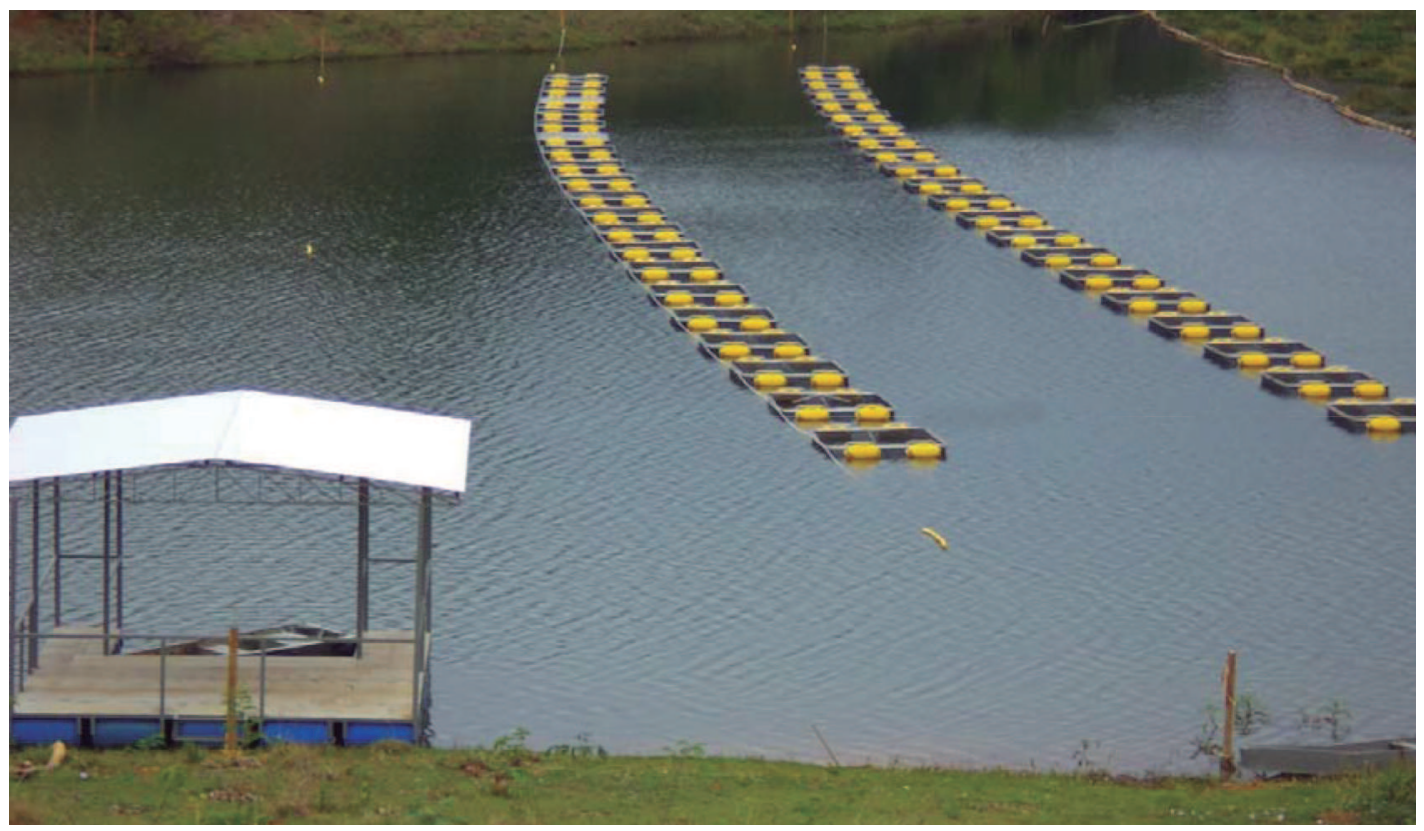

Figura 1- Tanques redes na água

Fonte: Pesquisa de campo, 2015.

Essa mudança de identidade fez com que os pescadores se afastassem das atividades pesqueiras, pois, a tradição deu lugar à técnica. A piscicultura exige o conhecimento que não foi repassado aos pescadores, assim, toda essa atividade é realizada por terceiros contratados pela cooperativa sob a supervisão dos técnicos do Nacab.

Essa mudança de pescadores artesanais para piscicultores, afeta diretamente a participação dos cooperados na produção da cooperativa. Podemos perceber isso nas falas dos cooperados quando perguntado qual era a sua participação na produção da cooperativa. Como observado no Gráfico 1, $57 \%$ nunca participaram de nenhuma atividade relacionada a produção da cooperativa, 18 \% já participou em algum momento das atividades da cooperativa, 13\% participa pouco em algumas atividades da cooperativa e $11 \%$ disseram que não participa, mas que tem o interesse em participar.

Os problemas da participação dos cooperados na produção da cooperativa também se reflete na comercialização, como podemos notar a seguir.

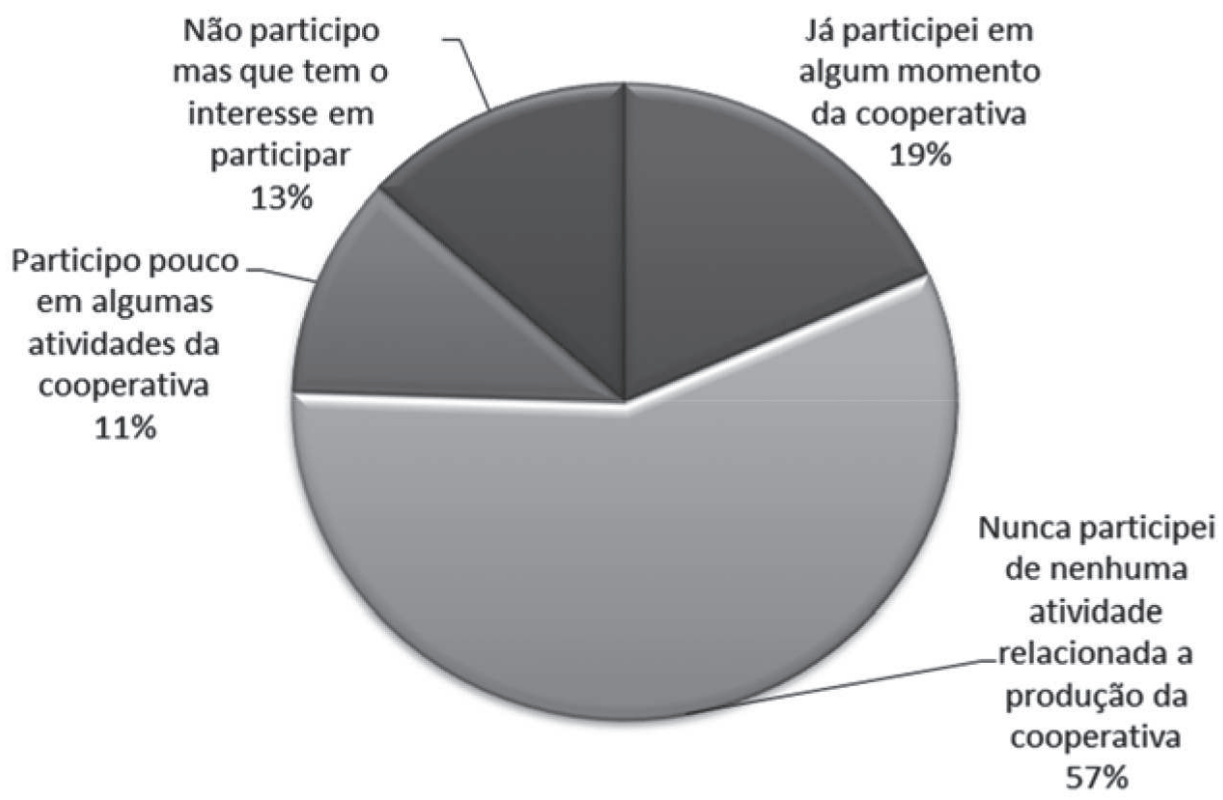

Gráfico 1 - Participação dos cooperados na produção da cooperativa

Fonte: Pesquisa de Campo, 2015. 


\subsection{Participação na Comercialização}

Outro aspecto que deve ser destacado neste estudo se refere ao processo de comercialização dos peixes. Como exposto anteriormente, os cooperados da COOPESCABRAÚNA não possuem os aparatos técnicos e organizacionais para participarem do processo de produção, em função da passagem da condição de pescador artesanal para piscicultores, em relação à comercialização isto não seria um problema, afinal, o processo de venda do peixe é o mesmo de outrora. Todavia, na prática, não é tão simples assim.

Decorre de maneira geral um problema que está ligado a tipologia da cooperativa. Espera-se que, numa cooperativa de pescadores os cooperados detenham o meio de produção - no caso, os tanquesrede - e a partir da entrega do produto para cooperativa e de um possível beneficiamento pela mesma, haveria uma oferta em grande número para o mercado local, visando um ganho de escala por entrega.

Entretanto, existem três problemas principais que puderam ser identificados na pesquisa: (I) a produção da cooperativa que tem previsão do funcionamento final de 280 tanques-rede atualmente funciona apenas 80. Dentre as causas principais está um atraso em mais de um ano na aquisição das Licenças Ambientais, configurando assim, em um entrave para o ganho em escala; (b) a cooperativa atualmente não possui um caminhão refrigerado para levar o peixe in natura; (c) além disso, não haveria, segundo conversa com os técnicos responsáveis, um grande mercado consumidor na região, sendo que a maioria das vendas atuais são em pequenas quantidades, feitas no boca a boca.

Diante de tal contexto, criou-se então duas formas de comercialização para COOPESCABRAÚNA. Como primeira opção, o cooperado pode ir até a cooperativa pegar (comprar) "sua cota" e revender no mercado local, conseguindo dessa forma abater o dinheiro que pagou para retirar "sua cota" e obter o lucro em cima da venda. Tal fato acarreta em diversos problemas no que se refere à participação e solidariedade na cooperativa, dentre eles, está a disputa entre os cooperados sobre o preço e a quem vender. De qualquer forma, não são todos que possuem condições de participar da comercialização, pois, como dito anteriormente, na cooperativa existem muitas pessoas idosas que não teriam condições de realizar essa atividade.

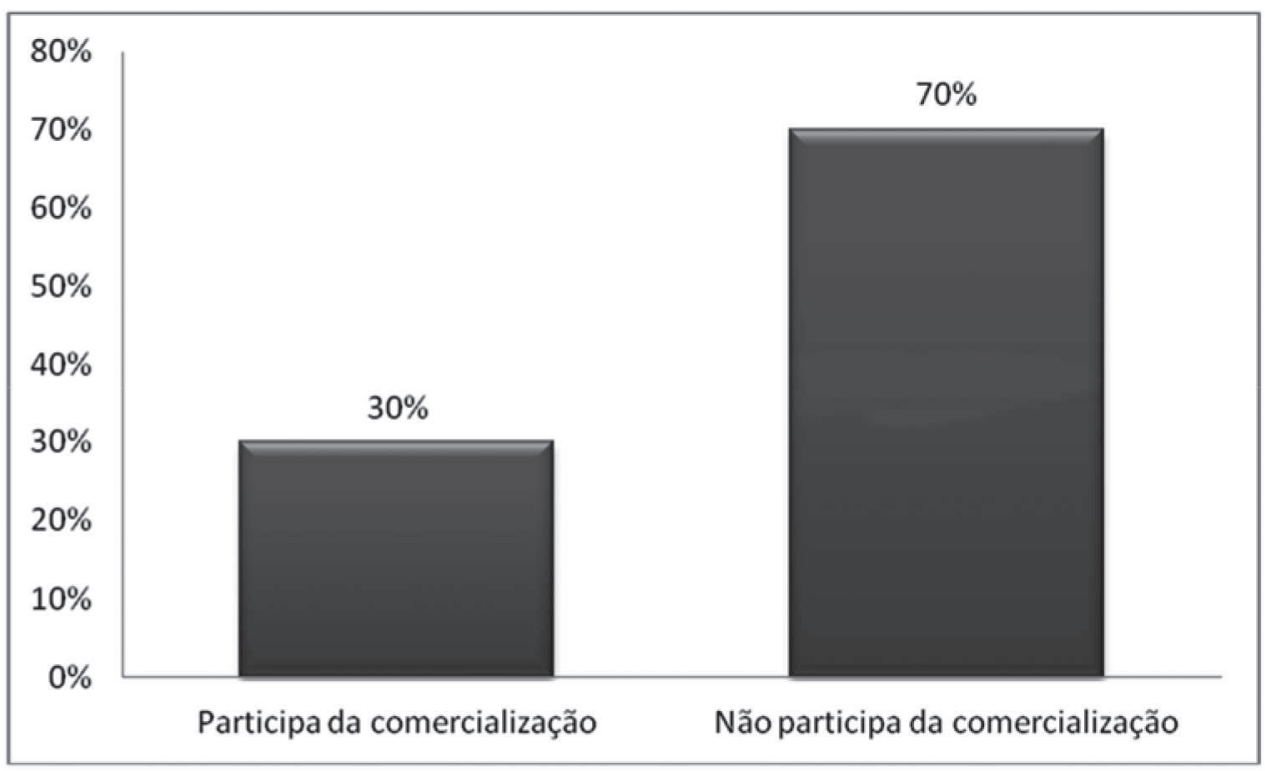

Gráfico 2 - Percepção dos cooperados sobre a comercialização.

Fonte: Pesquisa de campo, 2015.

Ademais, dentre outros motivos que dificultam a comercialização que foram apontados pelos cooperados estão: i) a distância entre a área do projeto e a cidade; ii) a falta de um veículo próprio para transportar o peixe e o custo de oportunidade, ou seja, o custo-benefício de deixar um afazer (trabalho, passeio, etc.) para procurar um vendedor para o produto.

A segunda opção de comercialização é esperar que alguns consumidores que demandam uma quantidade maior de peixe vão até a cooperativa. Nesse caso o cooperado retira a sua cota em dinheiro 
no ciclo de três meses, se de algum modo os cooperados participassem da etapa de produção não haveria nada de errado em apenas pegar sua retirada em dinheiro. Ademais, assim como na parte da produção a comercialização, nesse caso, fica estritamente a cargo dos técnicos.

Destaca-se, por fim, outro problema que está para além da opção de escolher vender o peixe por conta própria ou deixar que a cooperativa venda. Os técnicos do Nacab possuem a difícil tarefa de sensibilizar os cooperados da necessidade de reter o dinheiro do custo da produção e comercialização para que haja um novo ciclo de despesca. Isto se dá pelo fato de que durante todo o tempo de instalação do projeto os cooperados não entraram com nenhum aporte financeiro, isto é, no acordo do PRE ficou como condicionante a ser cumprida que até a implementação dos 280 tanques-rede - meta final do projeto - todo custeio seria por conta da empresa financiadora Brookfield. Essa isenção da contribuição

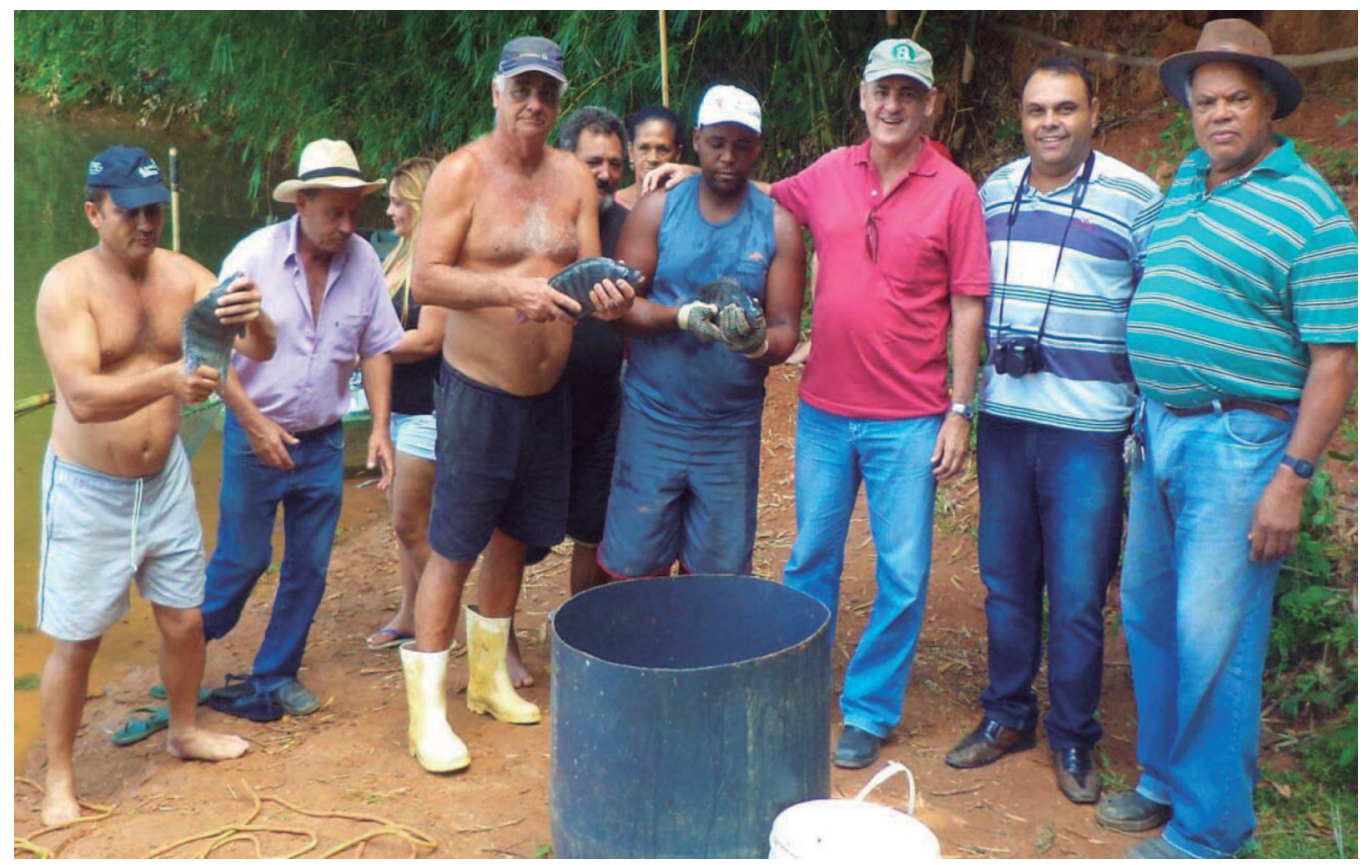

Figura 2 - Primeira despesca do ano de 2015

Fonte: Informativo do Nacab, 2015.

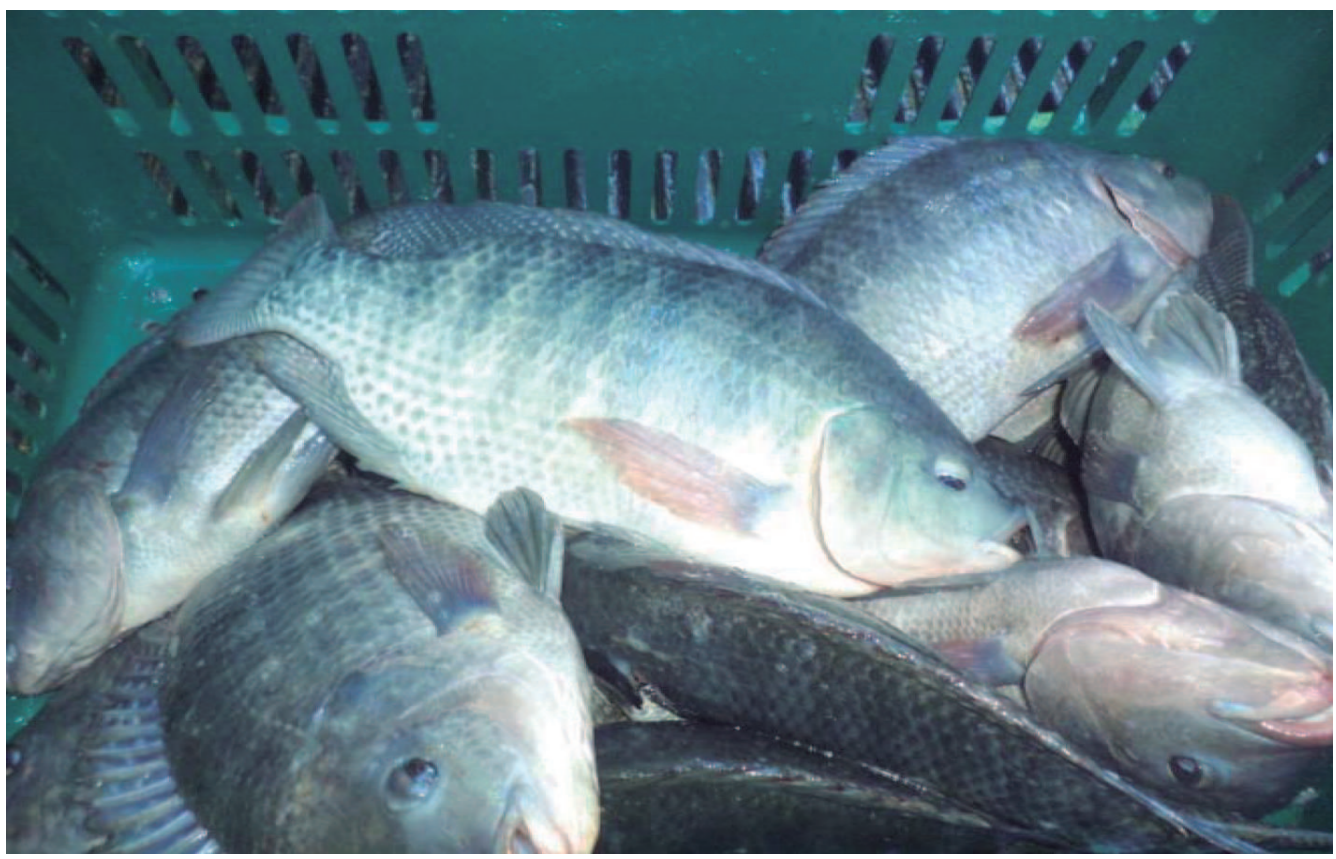

Figura 3 - Tilápias retiradas na primeira despesca

Fonte: Arquivo do Nacab, 2015. 
financeira por parte do cooperado se difere em muito de outros tipos de cooperativas, sobretudo nas cooperativas de piscicultores. Esse problema incide, com efeito, sobre a consciência de pertencimento à cooperativa, acarretando outros problemas quanto à participação social no dia a dia.

\section{Considerações finais}

Este trabalho propõe reflexões importantes sobre os princípios que orientam o cooperativismo em sua forma ideal, quais sejam: adesão voluntária e livre; gestão democrática; participação econômica dos membros; autonomia e independência; educação, treinamento e informação; intercooperação; e interesse pela comunidade. Concebidos durante o Congresso da Aliança Cooperativa Internacional (ACI), em Manchester, no ano de 1995 (OCB, 2017), o documento traz, por meio desses princípios, um conjunto de valores que norteariam a criação, a gestão social e econômica de cooperativas no mundo todo. Contudo, ao olhar para o objeto de estudo deste trabalho concluímos algumas incompatibilidades com tais pressupostos. Elencamos três:

I) Adesão voluntária e livre: a formação da cooperativa se deu como parte de um acordo maior, envolvendo empreendedor, comunidades atingidas e outros mediadores, isto é, não partiu de uma iniciativa da comunidade, foi parte de uma negociação. Embora o atingido, de forma individual, pudesse escolher não participar, via de regra, não faria, pois abdicaria de sua 'porção financeira' que não poderia resgatar pra si a não ser sendo membro da cooperativa.

II) Autonomia e independência: a falta de compatibilidade dos membros da cooperativa com a atividade de piscicultura em tanque-rede compromete sua autonomia frente ao processo de produção.

III) Gestão democrática: não é novo que o processo de gestão democrática nas cooperativas tem sido um grande entrave. Contudo, o processo conflituoso de cooperativas advindas de um PRE torna mais grave essa questão. Diversas decisões partem da mediação do conflito - o que coloca em contradição também a autonomia e independência - e não das assembleias, instância máxima de uma cooperativa.

Outro fator que demonstra uma especificidade desse tipo de cooperativa, refere-se a sua tipologia. A Organização das Cooperativas Brasileiras (OCB), considerado pelo Estado como o órgão máximo de representação das cooperativas tradicionais no país, formularam uma tipologia composta por treze ramos, onde, via de regra, uma cooperativa se enquadraria, quais sejam: Agropecuário, Consumo, Crédito, Educacional, Habitacional, Infraestrutura, Mineral, Produção, Saúde, Trabalho, Transporte, Turismo e Lazer.

Ao se fazer uma análise rápida sobre as possibilidades de enquadramento de uma cooperativa como a COOPESBRAÚNA nos ramos propostos pela OCB logo se tem a do tipo "produção" como a melhor opção: "[...] composto pelas cooperativas dedicadas à produção de um ou mais tipos de bens e produtos. As cooperativas detêm os meios de produção e os cooperados contribuem com trabalho conjunto" (OCB, 2017).

No entanto, é preciso considerar que participar de uma cooperativa de produção requer que os cooperados organizem a produção dos bens ou das mercadorias, processo esse inviável na COOPESCABRAÚNA, tendo em vista o alto grau de tecnificação necessária. A definição do ramo "agropecuário" poderia ser aceitável, tendo em vista que: "o ramo agropecuário reúne cooperativas de produtores rurais, agropastoris e de pesca. O papel da cooperativa é receber, comercializar, armazenar e industrializar a produção dos cooperados. Além, é claro, de oferecer assistência técnica, educacional e social" (OCB, 2017). Nesse caso, os meios de produção pertenceriam aos cooperados algo que também não aplica a cooperativa estudada.

De qualquer forma, é importante destacar que um empreendimento associativo como via de promoção de um PRE é ambicioso, mas possível. O mais importante, é que os atingidos sintam-se protagonistas de sua emancipação, o que pode ser possível ao desenvolver programas de Organização do Quadro Social (OQS), que visam melhorar a representatividade dos cooperados perante a cooperativa e o relacionamento desta para com eles. Logo, essa seria uma opção frente ao processo participativo conturbado pela qual as cooperativas advindas de cooperativas econômicas passam.

Não obstante ao caso aqui apresentado, o cooperativismo de fato tem se apresentado como uma alternativa para a geração de renda de grupos que se encontram a margem da sociedade. Existem vários exemplos espalhados pelo mundo. Em contraposição, também existirá experiências de um cooperativismo malogrado, aquém dos princípios de participação. 


\section{Fontes de financiamento}

Observatório Mineiro de Cooperativismo.

\section{Agradecimentos}

Agradecemos ao Observatório Mineiro de Cooperativismo pelo apoio financeiro a esta pesquisa e ao Núcleo de Assessoria às Comunidades Atingidas por Barragens (Nacab) pelo apoio em infraestrutura.

\section{Referências bibliográficas}

BARDIN, L. Análise de conteúdo. Lisboa: Edições 70, 2009.

BIALOSKORSKI NETO, S. Aspectos Econômicos das Cooperativas. Belo Horizonte: Mandamentos, 2006.

BIALOSKORSKI NETO, S. Um ensaio sobre desempenho econômico e participação em cooperativas agropecuárias. Revista de Economia e Sociologia Rural, Rio de Janeiro, v. 45, n. 1, 2007.

BIRCHALL, J.; SIMMONS, R. What motivates members to participate? A reworking of a theoretical model and some findings. In: KARAFOLAS, S; SPEAR, R; STRYJAN, Y. Local society \& global economy: the role of co-operatives. Naoussa: Hellin, 2002. cap. 2, p.131-157.

DAHL, R. A. Um prefácio à democracia econômica. Rio de Janeiro: Jorge Zahar, 1990.

FIGUEIREDO, M. et al. Reestruturação produtiva, terceirização e relações de trabalho na indústria petrolífera offshore da Bacia de Campos (RJ). Gestão de Produção, São Carlos, v. 14, n. 1, 2007.

FONTES FILHO, J. R. Governança cooperativa: participação e representatividade em cooperativas de crédito no Brasil. In: $\mathrm{V}$ encontro de pesquisadores latino-americanos de cooperativismo. 2008. Ribeirão Preto. Anais... Ribeirão Preto. 2008.p. 1-19.

HOLZMANN. L. Gestão cooperativa: limites e obstáculos à participação democrática. In: A economia solidária no Brasil: a autogestão como resposta ao desemprego. SINGER, Paul; SOUZA, André Ricardo de (Orgs.). São Paulo: Contexto, 2000. p. 49-62.

KLAES, L. S. Introdução ao Cooperativismo. Palhoça: Unisulvirtual, 2007.

LENCASTRE, M. P. A. Bondade, Altruísmo e Cooperação. Considerações evolutivas para a educação e a ética ambiental. Revista Lusófona de Educação, n.15, Lisboa: 2010.

MARCONI, M. de A.; LAKATOS, E. M. Técnicas de pesquisa: planejamento e execução de pesquisas, amostragens e técnicas de pesquisa, elaboração, análise e interpretação de dados. São Paulo: Atlas, 1988.

ORGANIZAÇÕES DAS COOPERATIVAS BRASILEIRAS (OCB). Ramos do cooperativismo. Brasília, 2017. Disponível em < http://www.somoscooperativismo.coop.br/\#/page-ocb >. Acesso em: 23 mar. 2017.

PERUZZO, C. M. K. Observação participante e pesquisa-ação. In: Duarte, J.; Barros, A. (org.), Métodos e técnicas de pesquisa em comunicação. São Paulo: Atlas, 2009.

PINTO, F. C. Uma História do Cooperativismo sob a Perspectiva Utópica. Revista de Administração e Contabilidade, v. 1, n. 1, p. 65-79, Junho/dezembro de 2009.

RÊGO, E. E. Cooperativismo e território: questões sobre a COAPECAL em Caturité-PB. 2009. 127f. Dissertação (Mestrado em Geografia) - Universidade Federal da Paraíba - UFPB, João Pessoa, 2009.

REISDORFER, V. K. Introdução ao cooperativismo. Santa Maria: Colégio Politécnico, 2014.

SALES, J. E. Cooperativismo: Origens e Evolução. Revista Brasileira de Gestão e Engenharia, n. 1, 2010.

SANTOS, E. S. A função social do contrato. Revista de Direito Privado, São Paulo: Editora Revista dos Tribunais, 2003. 
SCHNEIDER, J. O. Democracia, participação e autonomia cooperativa. 2. ed. São Leopoldo: UNI SINOS, 1999.

VALADARES, J. H. Moderna Administração de Cooperativas. Belo Horizonte: Farmacoop, 2004.

Recebido para publicação em 11/12/2016 e aprovado em 9/3/2017.

\footnotetext{
${ }^{7}$ Cooperativas criadas com o intuito de burlar leis trabalhistas colocando os pseudos-cooperados sob a subordinação de um empresário que terceiriza, na teoria, as cooperativas (FIGUEREIDO et al., 2007).

${ }^{8}$ A definição de Programa de Reativação Econômica surgiu na negociação entre comunidades atingidas, Nacab e empresas construtoras.

${ }^{9}$ De acordo com Fourier o rendimento máximo era obtido quando a falange era composta por 1.620 associados - dobro de 810 , número que indicava, segundo ele, a quantidade dos diferentes caracteres humanos (KLAES, 2007).

${ }^{10}$ Isso significava ir ao embate das ideias de Blanc.

${ }^{11}$ Existe uma disputa pela representação das cooperativas no Brasil, evidenciado, na prática, pelo embate entre a Organização das Cooperativas Brasileiras (OCB) e o movimento da Economia Solidária. O último faz duras críticas a primeira, acusando-os de colocar em risco valores como autogestão e cooperação frente a uma demasiada instrumentalização da gestão econômica. Sendo assim, no campo da disputa ideológica, ficou conhecido como o entrave entre as cooperativas tradicionais (ligadas a $\mathrm{OCB})$ e as cooperativas da Economia Solidária.
} 